\title{
Testing BOPA index in sewage affected soft-bottom communities in the north-western Mediterranean
}

\author{
J.A. de-la-Ossa-Carretero*, Y. del-Pilar-Ruso, F. Giménez-Casalduero, J.L. Sánchez-Lizaso \\ Department of Marine Sciences and Applied Biology, University of Alicante, Ap 99 E-03080 Alicante, Spain
}

\section{A R T I C L E I N F O}

\section{Keywords:}

Benthic indicators

BOPA index

Soft-bottoms

Opportunistic polychaetes

Amphipods

Mediterranean

Sewage

Water framework directive

\begin{abstract}
A B S T R A C T
The implementation of the European directive (ELD) 2000/60/EC has produced the development of several biotic indices based in benthic communities. These indices try to summarise ecological quality status of different communities. However, a universal index that works in all situations is difficult to establish, because there are several sources of variation. Therefore, there is the need for testing and validation of these indices which is required for making management decisions on different scales, and in different regions and communities. In this study we test one of these indices, BOPA index, developed by Dauvin and Ruellet [Dauvin, J.C., Ruellet, T., 2007. Polychaete/amphipod ratio revisited. Marine Pollution Bulletin $55,215-224]$ in five locations affected by sewage disposal. These disposals are often released via outfall into shallow subtidal habitats, leading to a common source of pollution in coastal marine environments. BOPA index provides a valuable overview of the gradient status of a benthic environment, discriminating between stations more affected by discharge. Nevertheless, BOPA index, used to establish the ecological quality status, seemed to overestimate the status and hence there is the need to calibrate the thresholds between EcoQs classes as defined for these medium-to-fine sand communities, which are characteristics of shallow sublittoral soft-bottoms of the north-western Mediterranean Sea.
\end{abstract}

() 2008 Elsevier Ltd. All rights reserved.

\section{Introduction}

Due to the increase in pressure on aquatic ecosystems which in turn is a consequence of continuous population growth, the European Parliament on 23 October 2000 established a framework for the Community to protect waters, the European directive (ELD) $2000 / 60 /$ EC. One object of the directive $2000 / 60$ is the protection and improvement of the aquatic environment with the progressive reduction of discharges and emissions. To comply, member states have to ensure that the highest ecological and chemical status possible is achieved, given impacts that could not reasonably have been avoided due to the nature of human activity or pollution.

A common source of pollution in coastal marine environments is sewage discharges that are often released via outfall into shallow subtidal habitats (McIntyre, 1995; Koop and Hutchins, 1996). This source is regulated by the urban waste water treatment directive (91/271/EEC), which established that there is a general need for secondary treatment of urban waste water to prevent the environment being adversely affected by the disposal of insufficientlytreated urban waste water. Member states will monitor and carry out any other relevant studies to verify that the discharge or disposal does not adversely affect the environment. Therefore, identification and characterisation of the locations affected by

\footnotetext{
* Corresponding author. Tel.: +34 96590 3400x2916; fax: +34 965909840.

E-mail address: ja.ossa@ua.es (J.A. de-la-Ossa-Carretero).
}

sewage discharge is necessary for efficient urban waste water management.

For the implementation of both directives it is necessary to have new tools to assess the anthropogenic impacts on marine habitats (Borja et al., 2003). This necessity has led to the development of different indexes based on soft-bottom communities, which summarise ecological status and ecological quality. The relationships between macrofaunal assemblages and the effect of contaminants on them have been described extensively in the literature, (Pearson and Rosenberg, 1978; Gray and Mirza, 1979; Dauvin, 1982; Warwick et al., 1990; Simboura et al., 1995; Estacio et al., 1997; Ellingsen, 2002; Morrisey et al., 2003; Guerra-García and García-Gómez, 2004).

Several biotic indexes have been developed with the aim of standardizing the use of benthic communities in order to establish marine habitat quality. Some of these indices are based on the classification of species (or groups of species) in several ecological groups representing specific sensitivity levels to disturbance. Two of the most widely used developed indexes are AMBI (AZTI, Borja et al., 2000) and BENTIX (Simboura and Zenetos, 2002). Both these indexes require classification to species level. However, this operation is labour intensive and time-consuming, especially for certain difficult groups such as spionid or cirratulid polychaetes, ampeliscid amphipods, etc. (De Biasi et al., 2003). Nevertheless there are others, such as BOPA index, in which the taxonomic effort is reduced. After an initial proposal which had only considered the ratio 


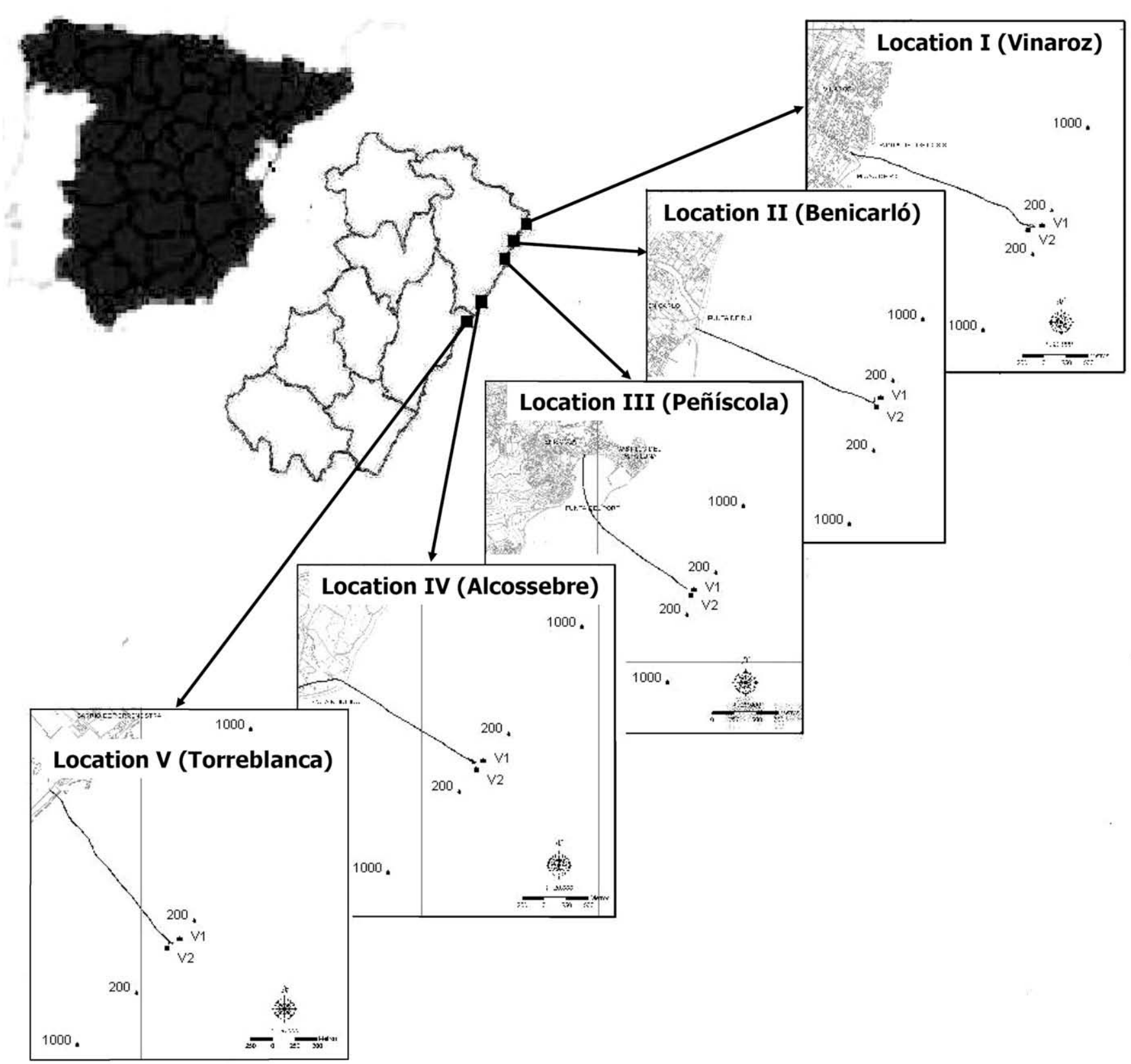

Fig. 1. Study area. Location of the five pipelines and the sampling stations.

amphipod/opportunistic polychaetes (Gomez Gesteira and Dauvin, 2000), BOPA has since been created and applied to the soft-bottom communities in the English Channel leading to the proposal of a

Table 1

Characteristics of the sewage outfalls analysed: pipeline length, outfall depth and sewage treatment.

\begin{tabular}{llll}
\hline & $\begin{array}{l}\text { Pipeline } \\
\text { length }(\mathrm{m})\end{array}$ & $\begin{array}{l}\text { Outfall } \\
\text { depth }(\mathrm{m})\end{array}$ & Sewage treatment \\
\hline Vinaroz (location I) & 2489 & 15.81 & Pre-treatment \\
Benicarló(location II) & 2141 & 14.58 & $\begin{array}{l}\text { Pre-treatment } \\
\text { Peñíscola (location III) }\end{array}$ \\
$\begin{array}{lll}\text { Alcossebre (location IV) } \\
\text { Torreblanca (location V) }\end{array}$ & 1886 & 15.50 & $\begin{array}{l}\text { Pre-treatment } \\
\end{array}$ \\
& 2175 & 14.00 & $\begin{array}{l}\text { Pre-treatment } \\
\text { Biological treatment } \\
\text { of activated sludge, } \\
\text { biological aerated filters }\end{array}$ \\
\hline
\end{tabular}

modified index (Dauvin and Ruellet, 2007). BOPA index is based on ratio opportunistic polychaetes and amphipods (except the genus Jassa). Opportunist polychaetes are resistant, indifferent or favoured by organically enriched sedimentary matter, whereas amphipods form a particular zoological group which is sensitive to significant increases in organic matter. The main advantages of this index, as well as the reduced taxonomic knowledge, are its independence of sampling protocols, its use of mesh sieves and of the surface unit chosen to express abundances, since this uses frequency data and the proportion of each category of organism (Pinto et al., 2009).

This index has already been used for monitoring the impact of pollution on different macrobenthic communities (Quintino et al., 2006; Dauvin et al., 2007; Pranovi et al., 2007; Munari and Mistri, 2007, 2008; Afli et al., 2008; Blanchet et al., 2008; Bouchet and Sauriau, 2008). However, a biotic index is unlikely to be universally 
Table 2

Results of ANOVA for BOPA values in each location for the factors distance, year and location. df, degrees of freedom, MS, medium squares, F of each factor = MS factor/MS residual because all the factors are orthogonal.

\begin{tabular}{|c|c|c|c|c|}
\hline \multirow[t]{2}{*}{ Source } & \multicolumn{4}{|c|}{ BOPA } \\
\hline & df & MS & $F$ & $p$ \\
\hline \multicolumn{5}{|l|}{ Location I } \\
\hline Distance & 2 & 0.004 & 5.867 & $0.005^{* *}$ \\
\hline Year & 3 & 0.001 & 1.862 & $0.146^{\mathrm{ns}}$ \\
\hline Distance $\times$ year & 6 & 0.001 & 1.621 & $0.157^{\mathrm{ns}}$ \\
\hline Error & 60 & & & \\
\hline \multicolumn{5}{|l|}{ Location II } \\
\hline Distance & 2 & 0.032 & 31.509 & $0^{* * * *}$ \\
\hline Year & 3 & 0.002 & 1.952 & $0.131^{\mathrm{ns}}$ \\
\hline Distance $\times$ year & 6 & 0.001 & 0.956 & $0.463^{\mathrm{ns}}$ \\
\hline Error & 60 & 0.001 & & \\
\hline \multicolumn{5}{|l|}{ Location III } \\
\hline Distance & 2 & 0.001 & 2.019 & $0.144^{\mathrm{ns}}$ \\
\hline Year & 3 & 0 & 1.077 & $0.368^{\mathrm{ns}}$ \\
\hline Distance $\times$ year & 6 & 0 & 0.516 & $0.793^{\mathrm{ns}}$ \\
\hline Error & 47 & 0 & & \\
\hline \multicolumn{5}{|l|}{ Location IV } \\
\hline Distance & 2 & 0.003 & 11.763 & $0^{* * *}$ \\
\hline Year & 3 & 0.006 & 20.015 & $0^{* * *}$ \\
\hline Distance $\times$ year & 6 & 0.001 & 2.283 & $0.048^{*}$ \\
\hline Error & 59 & 0 & & \\
\hline \multicolumn{5}{|l|}{ Location V } \\
\hline Distance & 2 & 0 & 1.252 & $0.293^{\mathrm{ns}}$ \\
\hline Year & 3 & 0.007 & 22.833 & $0^{* * *}$ \\
\hline Distance $\times$ year & 6 & 0.001 & 1.954 & $0.087^{\mathrm{ns}}$ \\
\hline Error & 60 & 0 & & \\
\hline
\end{tabular}

ns, no significant difference.

Significant at $p<0.05$.

** Significant at $p<0.01$

*** Significant at $p<0.001$.

applicable, because not all organisms are equally sensitive to all types of anthropogenic disturbances and thus are likely to respond differently to different types of perturbations (Pranovi et al., 2007; Dauvin et al., 2007; Afli et al., 2008). Indeed, the WFD recommends the use of reference sites to assess temporal changes in the ecological quality of water types under study, therefore these indices are required to test for departure from a reference or control situation (Quintino et al., 2006). It is interesting to assess the applicability, in terms of discriminating capacity, of biotic indices for environments in different state of conservation.

In this paper we apply BOPA index, with the criteria described by Dauvin and Ruellet (2007), to locations affected by sewage disposal by testing its ability to detect this impact and allowing us to come up with a future calibration for Mediterranean medium-tofine sand communities. These communities characterise shallow sublittoral soft-bottoms in the north-western Mediterranean Sea (Pérês and Picard, 1964; Sardá et al., 1996, 2000; Cardell et al., 1999) and these communities are common off the coast of Castellon (NE Spain). Several municipal treatment plants dump treated water into this area with a constant depth and uniform benthic community. Consequently, it is a site, with established pollution gradients, which is ideal for investigating the links between macrofaunal assemblages and the effect of contaminants.

\section{Materials and methods}

The study area is located off the Castellon Coast (NE Spain); five locations affected by sewage outfalls along $40 \mathrm{~km}$ of coast were analysed (Fig. 1). The minimum distance between outfalls is $7.62 \mathrm{~km}$ and the maximum $11.03 \mathrm{~km}$. These outfalls correspond to the villages of Vinaroz (location I), Benicarló (location II), Peñiscola (location III), Alcossebre (location IV) and Torreblanca (loca- tion $\mathrm{V}$ ). The mean length of the pipelines is $2138 \mathrm{~m}$ and the mean sewage outfall depth is $14.8 \mathrm{~m}$ (Table 1 ).

For each location, three distances from the discharge $(0,200$ and $1000 \mathrm{~m}$ ) were sampled, with two orientations (which correspond to the orientation of coastline, north and south). Samples were collected in July of 2004, 2005, 2006 and 2007, at approximately $15 \mathrm{~m}$ deep. Four Van Veen grab samples $\left(400 \mathrm{~cm}^{2}\right)$ were obtained at each station. Three samples were sieved through a $0.5 \mathrm{~mm}$ screen, and preserved in $10 \%$ formalin to count total infaunal abundance; differentiating abundance of amphipoda and abundance of oportunistic polychaete. We used the list of opportunistic polychaetes given in Gomez Gesteira and Dauvin (2000) according to Pearson and Rosenberg (1978) and Glemarec and Hily (1981).

Using these data we calculated BOPA index for each replicate

$\mathrm{BOPA}=\log \left(\frac{f p_{\mathrm{op}}}{f a+1}+1\right)$

where $f p_{\text {op }}$ is opportunistic polychaete frequency and $f a$ is amphipod (excluding the opportunistic Jassa amphipods) frequency (Dauvin and Ruellet, 2007).

The other sample was used to characterise the sediment (organic content, pH and granulometric analysis). Grain size analysis was then assessed by standard sieve fractionation (Folk, 1980; Holme and McIntyre, 1984). Organic content of dry sediment was estimated as the loss of weight after ashing. $\mathrm{pH}$ was analysed using a CRISON 507 pH-meter with electrode $\mathrm{pH} 52$.

Salinity, redox potential, dissolved $\mathrm{O}_{2}$ and $\mathrm{pH}$ of seawater was also measured in the year 2006 using a multiparametric probe Hydrolab $\mathrm{H} 20$.

Data of flow and water quality of sewage disposal (suspended solids, BOD (biologic oxygen demand), COD (chemical oxygen demand), phosphates, nitrates and turbidity) were provided us by CONSOMAR S.A and Entitat de Sanejament dAigues for the years 2004, 2005 and 2006.

BOPA values for each location were examined using two-factor analyses of variance (ANOVA) with distance and year as fixed factors; statistical software SYSTAT Version 8.0 was used.

Correlation between BOPA values and data of wastewater (flow, suspended solids, BOD, COD, phosphates, nitrates and turbidity), abiotic factors for sediment (granulometric analysis, organic matter, $\mathrm{pH}$ ) and seawater $(\mathrm{pH}$, redox potential, temperature and salinity) were determined using Pearson correlation, testing probability of each correlation coefficient with Bonferroni test.

The BOPA values were used to assign studied samples to the five (ecological quality status) classes suggested by WFD: "high" for unpolluted sites, "good" for slightly polluted sites, "moderate" for moderately polluted sites, "poor" for heavily polluted sites and "bad" for extremely polluted or azoic sites. The boundaries used between classes were ranked by Dauvin and Ruellet (2007).

\section{Results}

The ANOVA results showed significant differences in BOPA values between distances in locations I, II, III and IV; whereas there are no differences in location $\mathrm{V}$. Differences among years were detected in locations IV and V (Table 2).

Firstly, the differences between distances were due to the increase of BOPA index values for distance $0 \mathrm{~m}$ (Fig. 2). This happened in all the years in locations II and IV; in the years 2005, 2006 and 2007 in location III; and in year 2005 and 2006 in location I. With regard to differences between years (Fig. 2), detected significant differences were due to a decrease of BOPA index values during years 2005 and 2006, in locations IV and V.

Measurement of water quality showed better values in location $\mathrm{V}$, where values of flow, turbidity, suspended solids, BOD, COD, 
LOCATION I

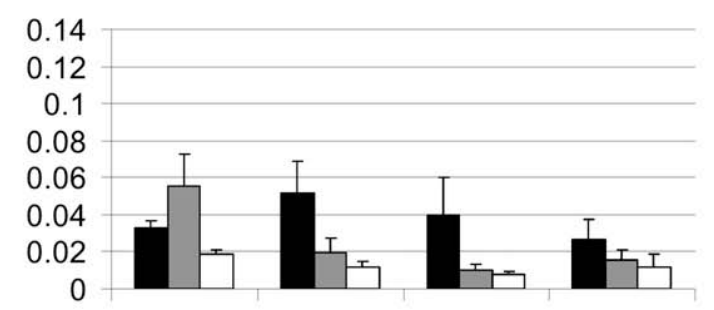

LOCATION II

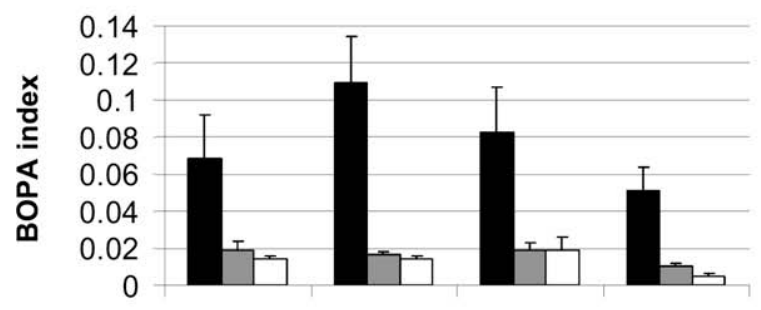

LOCATION IV
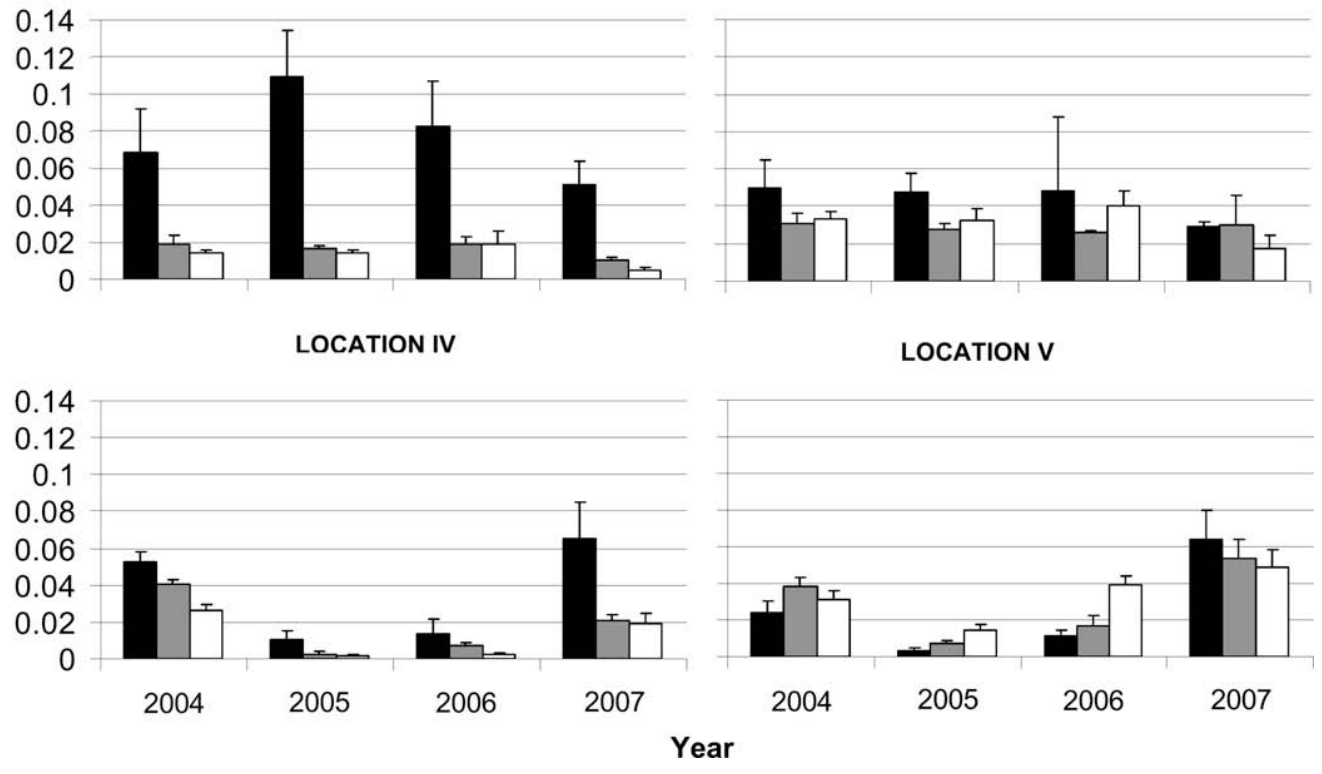

LOCATION V
Distances to the outfall

$0 \mathrm{~m} \quad \square 200 \mathrm{~m} \quad \square 1000 \mathrm{~m}$ 
Table 4

Means and standard errors of seawater parameters ( $\mathrm{pH}$, temperature, salinity, dissolved $\mathrm{O}_{2}$ and potential error), in each location and distance from outfall.

\begin{tabular}{|c|c|c|c|c|c|}
\hline & $\mathrm{pH}$ & Temperature $\left({ }^{\circ} \mathrm{C}\right)$ & Salinity $(\% o)$ & Dissolved $\mathrm{O}_{2}(\%)$ & Potential redox $(\mathrm{mV})$ \\
\hline \multicolumn{6}{|c|}{ Location I } \\
\hline $0 \mathrm{~m}$ & $8.24 \pm 0.00$ & $20.05 \pm 0.01$ & $38.39 \pm 0.00$ & $101.55 \pm 0.02$ & $52.00 \pm 4.47$ \\
\hline $200 \mathrm{~m}$ & $8.26 \pm 0.01$ & $20.08 \pm 0.07$ & $38.29 \pm 0.04$ & $104.05 \pm 1.54$ & $40.5 \pm 12.75$ \\
\hline $1000 \mathrm{~m}$ & $8.27 \pm 0.00$ & $20.11 \pm 0.11$ & $38.25 \pm 0.02$ & $104.15 \pm 1.05$ & $46.00 \pm 7.11$ \\
\hline \multicolumn{6}{|c|}{ Location II } \\
\hline $0 \mathrm{~m}$ & $8.4 \pm 0.00$ & $21.04 \pm 0.01$ & $38.35 \pm 0.02$ & $105.35 \pm 1.54$ & $14.5 \pm 10.96$ \\
\hline $200 \mathrm{~m}$ & $8.4 \pm 0.01$ & $20.89 \pm 0.03$ & $38.49 \pm 0.04$ & $100.75 \pm 0.65$ & $41.5 \pm 2.91$ \\
\hline $1000 \mathrm{~m}$ & $8.4 \pm 0.02$ & $21.02 \pm 0.01$ & $38.49 \pm 0.04$ & $99.25 \pm 0.11$ & $50.0 \pm 2.68$ \\
\hline \multicolumn{6}{|c|}{ Location III } \\
\hline $0 \mathrm{~m}$ & $8.27 \pm 0.00$ & $21.0 \pm 0.00$ & $38.1 \pm 0.00$ & $107.8 \pm 0.00$ & $-15 \pm 0.00$ \\
\hline $200 \mathrm{~m}$ & $8.26 \pm 0.00$ & $20.9 \pm 0.02$ & $38.1 \pm 0.02$ & $102.8 \pm 0.00$ & $9.5 \pm 7.82$ \\
\hline $1000 \mathrm{~m}$ & $8.26 \pm 0.00$ & $20.7 \pm 0.09$ & $38.3 \pm 0.02$ & $99.2 \pm 0.07$ & $17.0 \pm 20.12$ \\
\hline \multicolumn{6}{|c|}{ Location IV } \\
\hline $0 \mathrm{~m}$ & $8.07 \pm 0.00$ & $21.72 \pm 0.04$ & $38.4 \pm 0.02$ & $109.4 \pm 3.4$ & $-7 \pm 8.04$ \\
\hline $200 \mathrm{~m}$ & $8.06 \pm 0.00$ & $21.79 \pm 0.02$ & $38.4 \pm 0.02$ & $103.4 \pm 0.25$ & $67.5 \pm 1.56$ \\
\hline $1000 \mathrm{~m}$ & $8.06 \pm 0.01$ & $21.83 \pm 0.32$ & $38.4 \pm 0.02$ & $101.8 \pm 1.07$ & $75.5 \pm 13.64$ \\
\hline \multicolumn{6}{|c|}{ Location $V$} \\
\hline $0 \mathrm{~m}$ & $8.1 \pm 0.00$ & $22.3 \pm 0.25$ & $38.37 \pm 0.00$ & $108.4 \pm 3.8$ & $138 \pm 0.44$ \\
\hline $200 \mathrm{~m}$ & $8.07 \pm 0.01$ & $22.0 \pm 0.26$ & $38.42 \pm 0.02$ & $108.1 \pm 1.6$ & $135.5 \pm 6.03$ \\
\hline $1000 \mathrm{~m}$ & $8.14 \pm 0.00$ & $22.1 \pm 0.71$ & $38.62 \pm 0.11$ & $99.55 \pm 0.20$ & $144 \pm 1.79$ \\
\hline
\end{tabular}

Table 5

Means and standard errors of sediment parameters (granulometry, organic matter percentage and pH) in each location and distance from outfall.

\begin{tabular}{|c|c|c|c|c|c|c|c|}
\hline & \% Mud & $\%$ Fine sand & $\%$ Medium sand & $\%$ Coarsed sand & \% Gravel & $\%$ Organic matter & $\mathrm{pH}$ \\
\hline \multicolumn{8}{|c|}{ Location I } \\
\hline $0 \mathrm{~m}$ & $1.64 \pm 0.32$ & $75.63 \pm 2.76$ & $9.38 \pm 2.44$ & $8.75 \pm 1.33$ & $4.58 \pm 0.73$ & $5.39 \pm 1.11$ & $7.19 \pm 0.05$ \\
\hline $200 \mathrm{~m}$ & $2.68 \pm 0.65$ & $68.9 \pm 5.57$ & $12.9 \pm 3.14$ & $13.3 \pm 4.38$ & $2.17 \pm 0.24$ & $3.51 \pm 0.38$ & $7.30 \pm 0.07$ \\
\hline $100 \mathrm{~m}$ & $3.57 \pm 0.94$ & $73.94 \pm 3.04$ & $13.0 \pm 3.29$ & $6.928 \pm 0.38$ & $2.60 \pm 0.36$ & $4.09 \pm 0.55$ & $7.20 \pm 0.07$ \\
\hline \multicolumn{8}{|c|}{ Location II } \\
\hline $0 \mathrm{~m}$ & $1.64 \pm 0.75$ & $87.3 \pm 1.1$ & $4.18 \pm 0.46$ & $3.90 \pm 0.38$ & $2.93 \pm 0.80$ & $1.88 \pm 0.28$ & $7.21 \pm 0.08$ \\
\hline $200 \mathrm{~m}$ & $4.86 \pm 2.40$ & $74.4 \pm 4.65$ & $9.87 \pm 3.46$ & $5.21 \pm 0.54$ & $5.68 \pm 0.74$ & $2.64 \pm 0.33$ & $7.22 \pm 0.08$ \\
\hline $1000 \mathrm{~m}$ & $9.10 \pm 4.74$ & $72.35 \pm 4.62$ & $8.73 \pm 2.40$ & $5.58 \pm 0.32$ & $4.22 \pm 0.39$ & $2.05 \pm 0.34$ & $7.12 \pm 0.08$ \\
\hline \multicolumn{8}{|c|}{ Location III } \\
\hline 0 & $1.64 \pm 0.32$ & $75.6 \pm 2.76$ & $9.38 \pm 2.44$ & $8.75 \pm 1.33$ & $4.58 \pm 0.73$ & $7.61 \pm 2.31$ & $7.44 \pm 0.06$ \\
\hline $200 \mathrm{~m}$ & $2.68 \pm 0.65$ & $68.9 \pm 5.57$ & $12.9 \pm 3.14$ & $13.3 \pm 4.38$ & $2.17 \pm 0.24$ & $2.57 \pm 0.45$ & $7.37 \pm 0.04$ \\
\hline $1000 \mathrm{~m}$ & $3.57 \pm 0.94$ & $73.9 \pm 3.04$ & $13.0 \pm 3.29$ & $6.928 \pm 0.38$ & $2.60 \pm 0.36$ & $3.04 \pm 0.49$ & $7.34 \pm 0.04$ \\
\hline \multicolumn{8}{|c|}{ Location IV } \\
\hline $0 \mathrm{~m}$ & $0.64 \pm 0.15$ & $77 \pm 6.37$ & $16.8 \pm 6.43$ & $3.26 \pm 0.41$ & $2.30 \pm 0.53$ & $1.59 \pm 0.22$ & $7.30 \pm 0.07$ \\
\hline $200 \mathrm{~m}$ & $0.56 \pm 0.09$ & $73.2 \pm 4.11$ & $17.1 \pm 3.92$ & $4.56 \pm 0.56$ & $4.56 \pm 0.36$ & $2.05 \pm 0.21$ & $7.26 \pm 0.04$ \\
\hline 100 m & $1.24 \pm 0.15$ & $80.8 \pm 2.17$ & $9.03 \pm 2.14$ & $3.54 \pm 0.23$ & $5.38 \pm 0.42$ & $1.70 \pm 0.13$ & $7.32 \pm 0.07$ \\
\hline \multicolumn{8}{|c|}{ Location $V$} \\
\hline $0 \mathrm{~m}$ & $1.19 \pm 2.52$ & $90.7 \pm 0.92$ & $3.72 \pm 0.46$ & $2.67 \pm 0.42$ & $1.72 \pm 0.17$ & $1.78 \pm 0.24$ & $7.26 \pm 0.07$ \\
\hline $200 \mathrm{~m}$ & $2.52 \pm 0.58$ & $89.7 \pm 0.69$ & $3.51 \pm 0.35$ & $2.48 \pm 0.20$ & $1.74 \pm 0.24$ & $1.73 \pm 0.20$ & $7.26 \pm 0.06$ \\
\hline $1000 \mathrm{~m}$ & $1.35 \pm 1.01$ & $89.4 \pm 1.06$ & $4.96 \pm 0.85$ & $2.7 \pm 0.23$ & $1.60 \pm 0.15$ & $1.48 \pm 0.27$ & $7.26 \pm 0.04$ \\
\hline
\end{tabular}

On the one hand, this index is negatively correlated with amphipods, which are a particularly sensitive zoological group, not only to significant increases in organic matter but also to increases in other kinds of pollution including metals and hydrocarbons (Dauvin and Ruellet, 2007). The increased abundance of amphipods as we move away from the discharge, suggests that the environment was less stressed, since amphipods are more sensitive to pollution (environmental stress) than other marine species (Rand and Petrocelli, 1985; Arvai et al., 2002; Cesar et al., 2004; Riba et al., 2004). On the other hand, polychaete group contains both sensitive and tolerant species and they are found along the whole gradient from pristine to heavily disturbed areas (Olsgard et al., 2003). Some species showed significantly greater numbers of individuals at the sewage affected site while other species densities showed no difference or in some cases even a decrease (Dauer and Conner, 1980).The presence or absence of specific polychaetes in marine sediments, therefore, provides an excellent indi- cation of the condition or health of the benthic environment (Pocklington and Wells, 1992). Therefore the opportunistic polychaete/amphipod ratio worked as an indicator when studying the effects of sewage pollution.

Moreover, BOPA values showed significant positive correlation with waste water measurements: flow, suspended solid, phosphates, BOD, COD, conductivity and turbidity. In the locations where these factors are highest, the BOPA index increased near disposal. In location $\mathrm{V}$ disposal BOPA values were the lowest and values of water quality of sewage disposal (suspended solids, BOD, COD, phosphates, nitrates and turbidity) register the best values of the five disposals. In this way, the urban waste water treatment directive (91/271/EEC) established that there is a general need for secondary treatment of urban waste water to prevent the environment from being adversely affected. Requirements for discharges from urban waste water treatment plants which dump in sensitive areas, set by directive $91 / 271$, were accomplished by location V 
Table 6

Pearson correlation BOPA values with studied factors (BOD, biologic oxygen demand; COD, chemical oxygen demand) and Bonferroni probabilities.

\begin{tabular}{lcl}
\hline BOPA & Pearson correlation & Bonferroni probabilities \\
\hline Water disposal & & \\
$\mathrm{pH}$ & 0.019 & $0.868^{\mathrm{ns}}$ \\
Flow $\left(\mathrm{m}^{3} /\right.$ month) & 0.58 & $0^{* * *}$ \\
Suspended solids $(\mathrm{mg} / \mathrm{l})$ & 0.372 & $0.001^{* *}$ \\
BOD $(\mathrm{mg} / \mathrm{l})$ & 0.227 & $0.044^{*}$ \\
COD $(\mathrm{mg} / \mathrm{l})$ & 0.336 & $0.002^{* *}$ \\
Phosphates $(\mathrm{mg} / \mathrm{l})$ & 0.491 & $0^{* * *}$ \\
Nitrates $(\mathrm{mg} / \mathrm{l})$ & 0.1 & $0.381^{\mathrm{ns}}$ \\
Conductivity & 0.449 & $0^{* * *}$ \\
Turbidity (NTU) & 0.293 & $0.009^{* *}$ \\
Sea water & & \\
pH & 0.319 & $0.003^{* *}$ \\
Temperature $\left({ }^{\circ} \mathrm{C}\right)$ & -0.119 & 0.278 \\
Salinity $(\%)$ & -0.049 & 0.655 \\
$\mathrm{O}_{2}$ Dissolved $(\%)$ & 0.096 & 0.383 \\
Potential redox $(\mathrm{mV})$ & -0.244 & $0.025^{*}$ \\
Sediment & & \\
\% Mud & -0.034 & $0.53^{\mathrm{ns}}$ \\
\% Fine sand & 0.017 & $0.752^{\mathrm{ns}}$ \\
\% Medium sand & -0.084 & $0.117^{\mathrm{ns}}$ \\
\% Coarse sand & 0.192 & $0^{* * *}$ \\
\% Gravel & -0.096 & $0.075^{\mathrm{ns}}$ \\
\% Organic matter & 0.049 & $0.367^{\mathrm{ns}}$ \\
pH & -0.031 & $0.621^{\mathrm{ns}}$ \\
\hline
\end{tabular}

ns, no significant difference.

* Significant at $p<0.05$.

** Significant at $p<0.01$

**** Significant at $p<0.001$

waste water (phosphates $<2 \mathrm{mg} / \mathrm{l}$, nitrates $<15 \mathrm{mg} / \mathrm{l}$, BOD $<25 \mathrm{mg} / \mathrm{l}$ $\mathrm{O}_{2}$, COD $<125 \mathrm{mg} / \mathrm{l} \mathrm{O}_{2}$ and suspended solids $<35 \mathrm{mg} / \mathrm{l}$ ).

The issue of the assessments of the physicochemical status has been addressed by several authors (Bald et al., 2005; Rodríguez et al., 2006; Best et al., 2007; Simboura and Reizopoulou, 2008). BOPA index could be related to physicochemical status; this relation was studied analysing Pearson correlation of BOPA values with several seawater and sediment parameters which can vary according to the sewage discharges. However, in our study, there is only significant correlation with low Pearson coefficients for potential redox and $\mathrm{pH}$ of analysed seawater parameters and coarse sand percentage in sediment parameters. A decrease of potential redox and increase of $\mathrm{pH}$ produced an increase in BOPA values, indicating a relation of BOPA index with chemical quality of water especially with water oxygen saturation and possible hypoxia situation (Borja et al., 2006). Despite the fact that our study area has homogeneous bottom sediment with only soft changes in granulometry, coarse sand percentage showed significant correlation. This is due to the fact that sediment type defines habitats and their faunistic assemblages, hence weak changes in grain sizes of sediment could produce variations in the values of benthic indices (Llanso et al., 2002; Dauvin et al., 2007) .Other more changeable parameters, such as organic matter content, that showed significant correlations with BOPA assessing intertidal mudflats constrained by oyster farming (Bouchet and Sauriau, 2008), did not show significant correlation. However this would not be the first time that no correlation has been found between organic matter content in the sediment and biotic indices (Dauvin et al., 2007; Borja et al., 2000).

The principal aim of indices in directive WFD is to classify EcoQ status. We classified the areas affected by sewage outfall using an indicator developed by Dauvin and Ruellet (2007) for Atlantic communities. The results indicated that most of the stations were classified as having "good" status despite the presence of a disposal of waste water, only pre-treated in four of five outfalls. Only in the outfall with high flow, were the impacted stations classified as "moderate" in $16.67 \%$ of samples. We could be overestimating the ecological quality (EcoQ) of stations close to sewage outfalls, by not differentiating sufficiently well the boundary between "good" and "moderate" status. In fact, the index has classified sewage impacted areas as "good" and this could be due to the fact that the BOPA classification, ranked by Dauvin and Ruellet (2007), apportions a particularly wide range to the category "good".

Indices seem to generally overestimate the EcoQ status under different conditions. Bakalem et al. (2008) did not find any area with moderate status in a similar zone, applying BOPA index to shallow Algeria fine sand community, due to the high diversity of amphipodos in this community. Munari and Mistri (2007, 2008), classified the majority of stations in Tyrrhenian and Adriatic coastal lagoons as "good/high" using BOPA. They claim that amphipods associated with the common presence of macroalgae in Adriatic
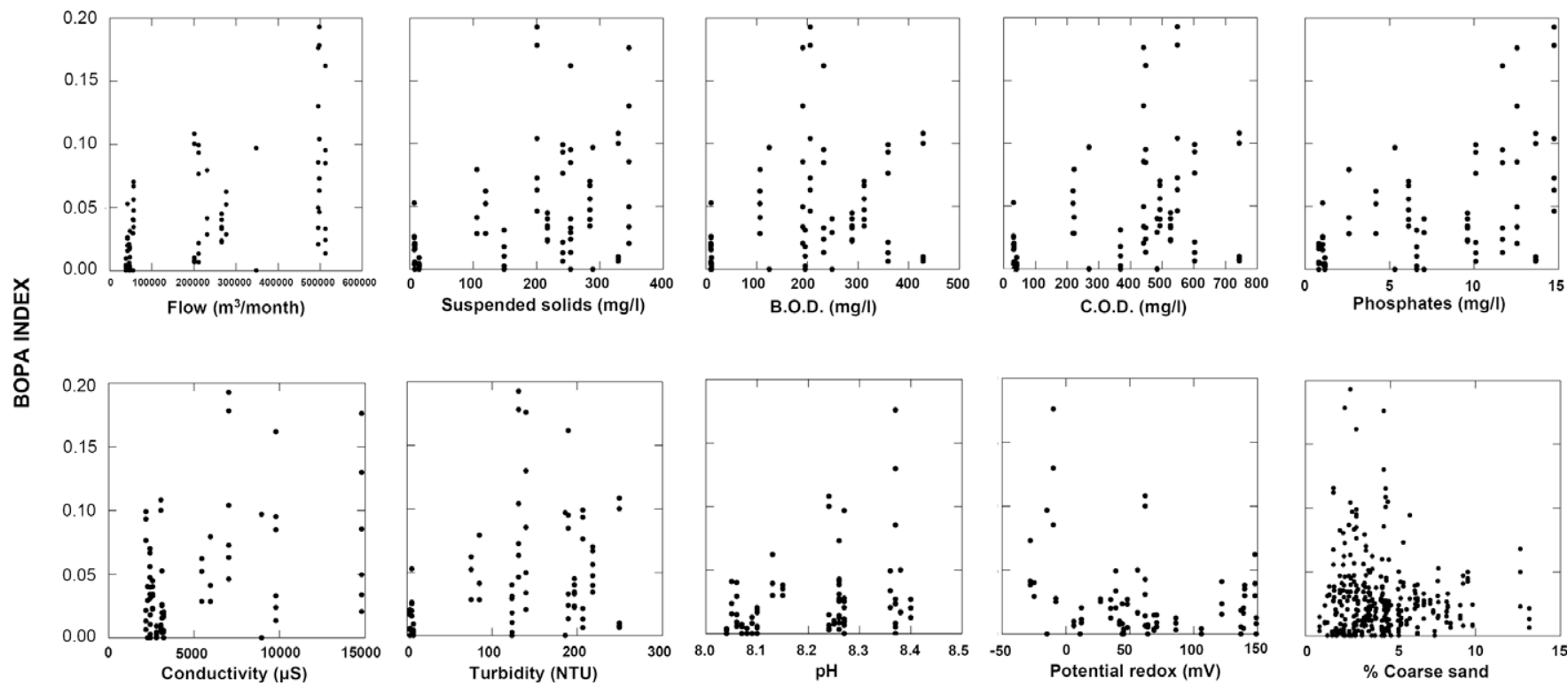

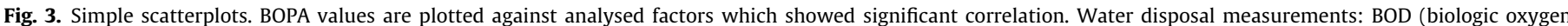

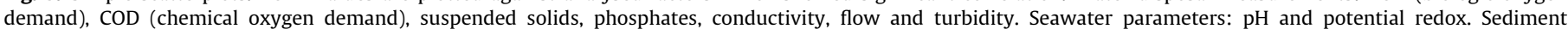
parameters: \% coarse sand. 


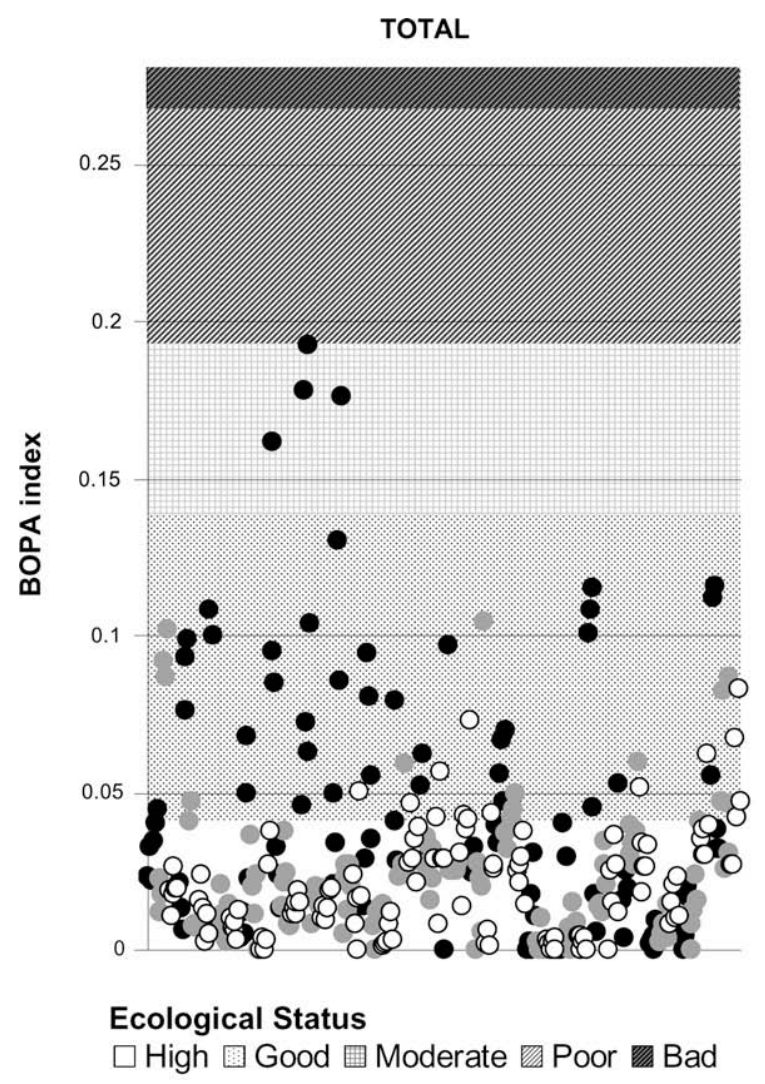

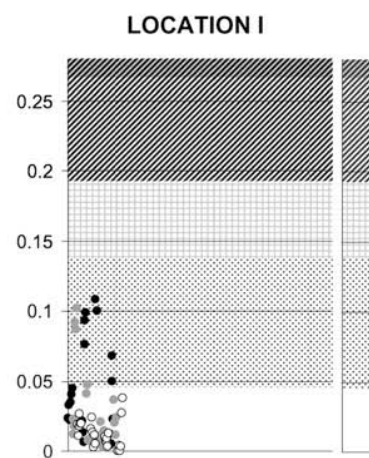

LOCATION II
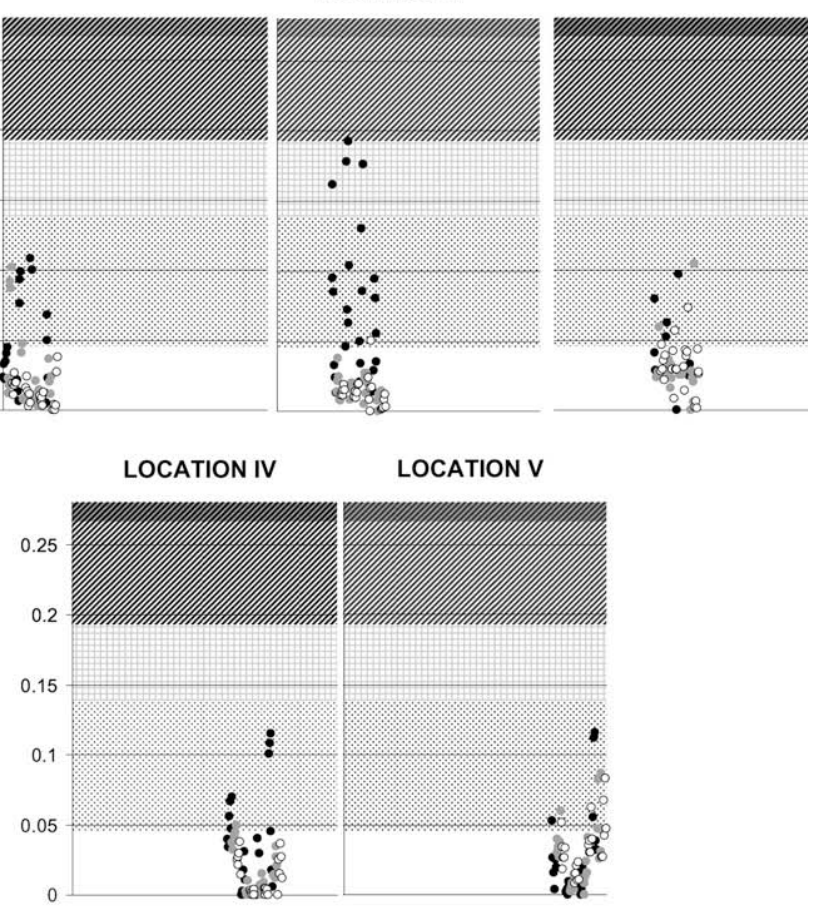

Distances to the outfall of samples station

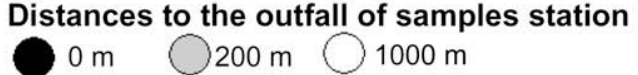

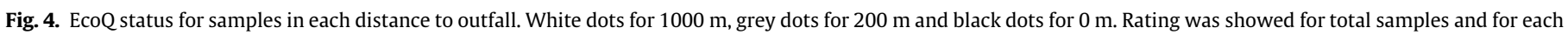
location.

transitional waters are probably sufficient to increase the ecological quality of the station through the BOPA model. Pranovi et al. (2007) also found that BOPA showed low discrimination in the Venice lagoon, classifying all the samples in the high category and, in the same way, Blanchet et al. (2008) found the same problem, BOPA classified a large majority of stations of the French Coast as acceptable ("good" or "high" status). Afli et al. (2008) also showed that off the Tunisian coast BOPA index appeared to be somewhat severe, classifying only two stations in moderate and poor statuses. An opposite case is the so-called 'paradox of estuarine qualitý (Dauvin et al., 2007), which established that transitional estuarine waters are naturally organic rich environments where stress-tolerant species are typical, so transitional environments would therefore likely be, by definition, characterised by low scores and hence low EcoQ values. In Quintino et al. (2006), several representative indices are shown unlikely to discriminate between changes in community structure, although they are sufficient to detect large scale differences which can be attributed to well-defined stressors (Quintino et al., 2006; Rees et al., 1990). Indeed the robust nature of the indicators on differing spatial spaces and under differing benthic conditions has not been rigorously assessed (Quintino et al., 2006). There is a need for understanding the links between the effects of human activity and changes in populations (ICES, 2004; Munari and Mistri, 2008) for each community and even area.

Another source of variability that it is necessary to keep in mind is the differences existing among ecoregions. The Mediterranean is a characteristic sea, being an oligotrophic, euhaline and microtidal environment. In other classification systems, such as chlorophyll biomass concentration or, dissolved inorganic nitrogen, there are different boundary limits and reference condition thresholds used by different member states and/or ecoregions (Simboura and Reiz- opoulou, 2008). Simboura and Reizopoulou (2008) in the Helenic area demonstrated that biotic indices perform differently on the ecoregion scale (e.g., Mediterranean, Atlantic) and on the water category scale (coastal, transitional waters).

A prerequisite for successful implementation of the European water framework directive in European waters is the intercalibration of the methods and scaling in accordance and in biological relevance to the normative definitions of WFD. The ecological quality status has become a priority issue of the directive and should be particularly tested on the upper and lower boundaries of the "good" class. Among these boundaries, the "good/moderate" one is essential because "moderate" status sites should be restored to "good" by the year 2015 (Simboura and Reizopoulou, 2008). The urgent need for assessing environmental quality within WFD using biological indices could produce erroneous conclusions. A universal index that works in all coastal areas is difficult to find because benthic communities vary widely.

For a correct assessment of a general ecological quality status of marine environments as well as for the indication of reference conditions, the natural variability of the indices on different temporal and spatial scales has to be assessed and taken into account (Reiss and Kröncke, 2005). So, it is necessary to use reference sites to assess temporal and spatial changes in the ecological quality classification, as WFD recommends. The objective of setting reference condition standards is to enable the assessment of the biological quality, against an existing 'pristine'/undisturbed site (or a site with very minor disturbance) (Muxika et al., 2007). In our study area, stations furthest from sewage outfalls could be considered as suffering minimal, impact from human activities. Meanwhile, a sampling station situated in location II outfall showed the highest disturbed situation. The mean \pm standard error of BOPA value obtained in minor impact stations was $0.021 \pm 0.002$ whereas it was 
$0.078 \pm 0.011$ in highest disturbed stations. Similar values were obtained applying BOPA index in Algeria fine sand community (Bakalem et al., 2008); where locations, a priori, considered less impacted (Fetzara, Jijel, Bou Ismail) obtained a mean \pm standard error of $0.016 \pm 0.0025$ and stations higher impacted (Alger-OH, Arzew-gab1, Oran) obtained $0.0599 \pm 0.0114$. Based on these values and considering disturbed station in moderate status (non-acceptable situation) and unimpacted stations in good status (acceptable situation); the value for the "good/moderate" class boundary in BOPA index, essential boundary to calibrate, should be situated lower than Dauvin and Ruellet (2007) and for this community, a value around $0.05 \pm 0.028$ could be considered. The decrease in the value of this boundary was also reported in Ruellet and Dauvin (2007), doing an analysis of these threshold values with data from the Seine estuary. However, a larger dataset, containing an equal number of samples from each EcoQ, must be used to determine the new thresholds during an intercalibration exercise (Ruellet and Dauvin, 2007).

There is the need for testing and validation of these boundaries and indicators in several similar areas, these being required to establish a well-defined boundary and facilitate making management decisions at different scales and for each different region and community. Such partitioning would need to be carried out using big datasets containing all the ecological situations encountered in Europe and for each type of benthic community (Ruellet and Dauvin, 2007). Further validation is required especially where one indicator over-estimates the ecological status for poor areas and underestimates it for good areas.

\section{Conclusions}

BOPA index may provide a good overview of the gradient status of a benthic environment; nevertheless using it to establish the true ecological status of a specific site is difficult and requires calibrating the thresholds between EcoQs classes defined for each community and biogeographically area finding reference conditions for each type of habitat. The difficulty related to the use of BOPA index in environments subjected to stressors could be saved reducing interference due to the environmental gradients which varies seasonally and spatially, and probably smooth the stressors effects. This could be made possible by choosing reference values in similar areas without pollution. These practical limits of the used ecological tool must be acknowledged in order to properly evaluate and manage waste water disposal.

\section{Acknowledgements}

We gratefully acknowledge CONSOMAR S.A and Entitat de Sanejament dAigües for their financial contribution to this project. We are also grateful to the University of Alicante for awarding a predoctorate grant. We also thank the staff of the Department of Marine Sciences and Applied Biology, especially Y. Mugica, M. Diaz-Valdes and C. Celdrán for their inestimable collaboration. We also acknowledge the contributions of the reviewer of this manuscript and Dr. Ian Woollard, for reviewing the English version.

\section{References}

Afli, A., Ayari, A., Zaabi, S., 2008. Ecological quality of some Tunisian coast and lagoon locations, by using benthic community parameters and biotic indices. Estuarine, Coastal and Shelf Science 10.1016/j.ecss.2008.08.010.

Arvai, J.L., Levings, C.D., Harrison, P.J., Neill, W.E., 2002. Improvement of the sediment ecosystem following diversion of an intertidal sewage outfall at the Fraser river estuary, Canada, with emphasis on Corophium salmonis amphipoda. Marine Pollution Bulletin 44, 511-519.

Bakalem, A., Ruellet, T., Dauvin, J.C., 2008. Benthic indices and ecological quality of shallow Algeria fine sand community. Ecological Indicators. 10.1016/ j.ecolind.2008.05.008.
Bald, J., Borja, A., Muxika, I., Franco, J., Valencia, V., 2005. Assessing reference conditions and physico-chemical status according to the European wate framework directive: a case-study from the Basque Country (Northern Spain). Marine Pollution Bulletin 50, 1508-1522.

Best, M.A., Wither, A.W., Coates, S., 2007. Dissolved oxygen as a physico-chemical supporting element in the water framework directive. Marine Pollution Bulletin 55, 53-64.

Blanchet, H., Lavesque, N., Ruellet, T., Dauvin, J.C., Sauriau, P.G., Desroy, N., Desclaux, C., Leconte, M., Bachelet, G., Janson, A.L., Bessineton, C., Duhamel, S., Jourde, J. Mayot, S., Simon, S., de Montaudouin, X., 2008. Use of biotic indices in semienclosed coastal ecosystems and transitional waters habitats - implications for the implementation of the European water framework directive. Ecological Indicators 8, 360-372.

Borja, A., Franco, J., Perez, V., 2000. A marine biotic index to the establish ecology quality of soft-bottom benthos within European estuarine coastal environments. Marine Pollution Bulletin 40, 1100-1114.

Borja, A., Muxika, I., Franco, J., 2003. The application of a marine biotic index to different impact sources affecting soft-bottom benthic communities along European coasts. Marine Pollution Bulletin 46, 835-845.

Borja, A., Muxika, I., Franco, J., 2006. Long-term recovery of soft-bottom benthos following urban and industrial sewage treatment in the Nervión estuary (southern Bay of Biscay). Marine Ecology Progress Series 313, 4355.

Bouchet, V.M.P., Sauriau, P.G., 2008. Influence of oyster culture practices and environmental conditions on the ecological status of intertidal mudflats in the Pertuis Charentais (SW France): a multi-index approach. Marine Pollution Bulletin. 10.1016/j.marpolbul.2008.07.010.

Cardell, M.J., Sardà, R., Romero, J., 1999. Spatial changes in sublittoral soft-bottom polychaete assemblages due to river inputs and sewage discharges. Acta Oecologica 20, 343-351.

Cesar, A., Martín, A., Marín-Guirao, L., Vita, R., 2004. Amphipod and sea urchin tests to assess the toxicity of Mediterranean sediments: the case of Portman Bay Scientia Marina 68, 205-213.

Dauer, D.M., Conner, W.G., 1980. Effects of moderate sewage on benthic polychaete populations. Estuarine and Coastal Marine Science 10, 335-346.

Dauvin, J.C., 1982. Impact of Amoco Cadiz oil spill on the muddy fine sand Abra alba and Melinna palmata community from the Bay of Morlaix. Estuarine Coastal Shelf Science 14, 517-531.

Dauvin, J.C., Ruellet, T., 2007. Polychaete/amphipod ratio revisited. Marine Pollution Bulletin 55, 215-224.

Dauvin, J.C., Ruellet, T., Desroy, N., Janson, A.-L., 2007. The ecology quality status of the Bay of Seine and the Seine estuary: use of biotic indices. Marine Pollution Bulletin 55, 241-257.

De Biasi, A.M., Bianchi, C.N., Morri, C., 2003. Analysis of macrobenthic communities at different taxonomic levels: an example from an estuarine environment in the Ligurian Sea NW Mediterranean. Estuarine, Coastal and Shelf Science 58, 99106.

Ellingsen, K.E., 2002. Soft-sediment benthic biodiversity on the continental shelf in relation to environmental variability. Marine Ecology Progress Series 232, 15 27.

Estacio, F.J., García-Adiego, E.M., Fa, D.A., García-Gómez, J.C., Daza, J.L., Hortas, F. Gómez-Ariza, J.L., 1997. Ecological analysis in a polluted area of Algeciras Bay Southern Spain: external 'versus' internal outfalls and environmental implications. Marine Pollution Bulletin 34, 768-779.

Folk, R.L., 1980. Petrology of Sedimentary Rocks. Hemphill Publishing Co Austin, TX.

Glemarec, M., Hily, C., 1981. Perturbations apportées à la macrofaune benthique de la baie de Concarneau par les effluents urbains et portuaires. Acta Oecologica, Acta Applicata 2, 139-150.

Gomez Gesteira, J.L., Dauvin, J.C., 2000. Amphipods are good bioindicators of the impact of oil spills on soft-bottom macrobenthic communities. Marine Pollution Bulletin 40, 1017-1572.

Gray, J.S., Mirza, F.B., 1979. A possible method for detecting pollution induced disturbance on marine benthic communities. Marine Pollution Bulletin 10, 142146.

Guerra-García, J.M., García-Gómez, J.C., 2004. Soft bottom mollusc assemblages and pollution in a harbour with two opposing entrances. Estuarine, Coastal and Shelf Science 60, 273-283.

Holme, N.A., McIntyre, A.D., 1984. Methods for the Study of Marine Benthos, second ed. Blackwell Scientific Publication, London.

ICES, 2004. Report of the Study Group on Ecological Quality Objectives for Sensitive and for Opportunistic Benthos Species. ICES CM, ACE01, pp. 1-41.

Koop, K., Hutchins, P., 1996. Disposal of sewage to the ocean a sustainable solution? Marine Pollution Bulletin 33, 121-123.

Llanso, R.J., Scott, L.C., Dauer, D.M., Hyland, J.L., Russell, D.E., 2002. An estuarine benthic index of biotic integrity for the Mid-Atlantic Region of the United States. I. Classification of assemblages and habitat definition. Estuaries 25 1219-1230.

McIntyre, A.D., 1995. Human impact on the oceans: the 1990s and beyond. Marine Pollution Bulletin 31, 147-151.

Morrisey, D.J., Turner, S.J., Mills, G.N., Williamson, R.B., Wise, B.E., 2003. Factors affecting the distribution of benthic macrofauna in estuaries contaminated by urban runoff. Marine Environmental Research 55, 113-136.

Munari, C., Mistri, M., 2007. Evaluation of the applicability of a fuzzy index of ecosystem integrity (FINE) to characterize the status of Tyrrhenian lagoons. Marine Environmental Research 64, 629-638. 
Munari, C., Mistri, M., 2008. The performance of benthic indicators of ecological change in Adriatic coastal lagoons: throwing the baby with the water? Marine Pollution Bulletin 56, 95-105.

Muxika, I., Borja, A., Bald, J., 2007. Using historical data, expert judgment and multivariate analysing assessing reference conditions and benthic ecological status, according to the European water framework directive. Marine Pollution Bulletin 55, 16-29.

Olsgard, F., Brattegard, T., Holthe, T., 2003. Polychaetes as surrogates for marine biodiversity: lower taxonomic resolution and indicator groups. Biodiversity and Conservation 12, 1033-1049.

Pearson, T.H., Rosenberg, R., 1978. Macrobenthic succession in relation to organic enrichment and pollution of the marine environment. Oceanography and Marine Biology. An Annual Review 16, 229-311.

Pérês, J.M., Picard, J., 1964. Nouveau manuel de bionomie benthique de la mer Méditerranée. Bulletin Travaux Station Marine d'Endoume 31, 1-138.

Pinto, R., Patrício, J., Baeta, A., Fath, B.D., Neto, J.M., Marques, J.C., 2009. Review of estuarine biotic indices to assess benthic condition. Ecological Indicators 9, 125.

Pocklington, P., Wells, P.G., 1992. Polychaetes. Key taxa for marine environmental quality monitoring. Marine Pollution Bulletin 24, 593-598.

Pranovi, F., Da Ponte, F., Torricelli, P., 2007. Application of biotic indices and relationship with structural and functional features of macrobenthic community in the lagoon of Venice: an example over a long time series of data. Marine Pollution Bulletin 54, 1607-1618.

Quintino, V., Elliot, M., Rodrigues, A.M., 2006. The derivation, performance and role of univariate and multivariate indicators of benthic change: case studies of differing spatial scales. Journal of Experimental Marine Biology and Ecology 330, 368-382.

Rand, G., Petrocelli, S., 1985. Fundamentals of Aquatic Toxicology. Hemisphere Corporation, Washington, DC. p. 665.

Reiss, H., Kröncke, I., 2005. Seasonal variability of benthic indices: an approach to test the applicability of different indices for ecosystem quality assessment. Marine Pollution Bulletin 50, 1490-1499.
Rees, H.L., Moore, D.C., Pearson, T.H., Elliott, M., Service, M., Pomfret, J., Johnson, D., 1990. Procedures for the Monitoring of Marine Benthic Communities at UK Sewage Sludge Disposal Sites. Scottish Fisheries Information Pamphlet 18, p. 78.

Ruellet, T., Dauvin, J.C., 2007. Benthic indicators: analysis of the threshold values of ecological quality classifications for transitional waters. Marine Pollution Bulletin 54, 1707-1714.

Riba, I., Conradi, M., Forja, J.M., DelValls, T.A., 2004. Sediment quality in the Guadalquivir estuary: lethal effects associated with the Aznalcollar mining spill. Marine Pollution Bulletin 48, 144-152.

Rodríguez, J.G., Tueros, I., Borja, A., Belzunce, M.J., Franco, J., Solaun, O., Valencia, V., Zuazo, A., 2006. Maximum likelihood mixture estimation to determine metal background values in estuarine and coastal sediments within the European water framework directive. Science of the Total Environmental 370, 278-293.

Sardá, R., Pinedo, S., Martin, D., 1996. Seasonal dynamics of macroinfaunal key species inhabiting shallow soft-bottoms in the Bay of Blanes NW Mediterranean. Acta Oecologica 20 (4), 315-326.

Sardá, R., Pinedo, S., Gremare, A., Taboada, S., 2000. Changes in the dynamics of shallow sandy-bottom assemblages due to sand extraction in the Catalan Western Mediterranean Sea. ICES Journal of Marine Science 57, 1446-1453.

Simboura, N., Zenetos, A., Panayotidis, P., Makra, A., 1995. Changes in benthic community structure along an environmental pollution gradient. Marine Pollution Bulletin 307, 470-474.

Simboura, N., Zenetos, A., 2002. Benthic indicators to use in ecological quality classification of Mediterranean soft bottom marine ecosystems, including a new biotic index. Mediterranean Marine Science 3, 77-111.

Simboura, N., Reizopoulou, S., 2008. An intercalibration of classification metrics of benthic invertebrates in coastal and transition ecosystems of the Eastern Mediterrranean ecoregion (Greece). Marine Pollution Bulletin 56, 116-126.

Warwick, R.M., Platt, H.M., Clarke, K.R., Agard, J., Gobin, J., 1990. Analysis of macrobenthic and meiobenthic community structure in relation to pollution and disturbance in Hamilton Harbour, Bermuda. Journal Experimental Marine Biology, Ecology 138, 119-142. 